\title{
Empirical Research in Railway Transport Passengers' Interest in the Utilisation of Progressive Methods of Passenger Handling
}

\author{
Eva Brumercikova ${ }^{1, *}$ and Bibiana Bukova ${ }^{1}$ \\ ${ }^{1}$ University of Zilina, Faculty of Operation and Economics of Transport and Communications, Department of Railway Transport, \\ Univerzitna 8215/1, 01026 Zilina, Slovakia
}

\begin{abstract}
New technologies utilised abroad offer passengers a wide variety of options that can be adapted to passengers' needs. The application of progressive ways of passenger handling requires the provision of integrated transport systems. Thanks to innovative technologies carriers can extend their offering of transport services with brand new services enabled with these technologies. The article presents the results of empirical research in railway transport passengers' interest in the utilisation of progressive methods of passenger handling in the Slovak Republic.
\end{abstract}

\section{Introduction}

Many countries not only in Europe but also in America and Asia utilise there in the sphere of public passenger transport some new innovative technologies and systems which improve the quality of transport services. Innovations in transport technologies, namely in the area of passenger handling, introduce a wide spectrum of options to adapt the infrastructure to passengers' needs. Technologies used abroad provide passengers with comfort and convenience [1,2].

The following technologies are commonly applied in foreign countries: NFC (Near Field Communication), and EMV (Europay/MasterCard/VISA). The newest technology which for example utilises electronic identification cards of citizens (ID cards) to identify a passenger and to calculate a fare is the Account Based Ticketing ("ABT") technology

\section{Empirical Research in the Problem}

The analysis of passengers' interest in new ways of handling passengers in railway transport stems from empirical research.

The Selection of a Basic Group Size

The minimum count of questionnaires was calculated with the formula (1) [3-5].

$$
n \geq \frac{p *(1-p)}{\frac{e^{2}}{z^{2}}+\frac{p *(1-p)}{N}}
$$

where:

$n-$ minimum count of questionnaires from respondents,

$z$ - value corresponding to a selected significance level,

$p$ - relative percent $(\%)$ occurrence,

$e$-permissible measurement error expressing the percentage in which the found value can differ from the actual value of the basic group,

$N-$ the size of the basic group.

\footnotetext{
* Corresponding author: eva.brumercikova@,fpedas.uniza.sk
}

\section{The Evaluation of Empirical Research}

The questionnaire was aimed at existing and potential customers of railway companies in Slovakia. The goal of the questionnaire was to find out what method of payment was most frequently used by respondents when buying a travel document, together with providing a reason why they used that method most frequently. [6]Another goal was to find out if respondents knew some other methods of payment for a travel document which are used abroad, and if they were interested in utilising one of technologies mentioned above. [7]

Total number of respondents was 519, out of which 269 ones responded using a personal questionnaire and 250 ones responded using an electronic questionnaire provided by Google. Return of questionnaires (out of total 519 respondents) was $100 \%$. Based on the Table 1 a permissible measurement error calculated using the formula (1) was expressed; it tells about the percentage in which the found value can differ from the actual value of the basic group.

Table 1. Permissible Error of Measurement.

\begin{tabular}{|c|c||c|c|}
\hline $\begin{array}{c}\text { Permissible } \\
\text { Error }\end{array}$ & $\begin{array}{c}\text { Number of } \\
\text { Questionnair } \\
\text { es }\end{array}$ & $\begin{array}{c}\text { Permissible } \\
\text { Error }\end{array}$ & $\begin{array}{c}\text { Number of } \\
\text { Questionnair } \\
\text { es }\end{array}$ \\
\hline 2 & 2339 & 6 & 264 \\
\hline 3 & 1049 & 7 & 194 \\
\hline 4 & 592 & 8 & 149 \\
\hline 5 & 380 & 9 & 118 \\
\hline & & 10 & 96 \\
\hline
\end{tabular}

\section{Identification Data about Respondents}

The base for empirical research evaluation is formed with the analysis of respondents' structure according to 
demographic criteria. With regard to the article scope we present only some data. $58 \%$ of men participated in the empirical research; the most frequent age group is expressed in the interval 26 - 40 years (almost 50\%). With regard to the achieved education of respondents the following grades were present: primary education: $9 \%$, secondary education without school leaving examination (A Levels): 14\%, secondary education with school leaving examination (A Levels): $33 \%$, and university education: $44 \%$ respondents. The biggest group of respondents $(61 \%)$ were the employees.

\section{Current Method of Payment for a Travel Document Used by Respondents}

Currently there in passenger railway transport it is possible to use 5 payment options to buy a travel document: cash, cashless with authorisation (PIN code), cashless contactless, Internet banking and purchase of an SMS ticket. Respondents, who participated in the empirical research, use only the following 4 payment options:

- cash payment system: $44 \%$ - mostly passengers utilising free transport,

- cashless payment system with authorisation: $12 \%$,

- cashless payment system contactless: $19 \%$,

- internet banking: $25 \%$.

Respondents expressed their opinion on cashless payment where better part of responses was positive, however, some respondents also had a negative opinion; they prefer cash payment system and they do not trust in cashless payment; they consider it dangerous and untrustworthy in some cases. [8]

\section{The Respondents' Interest in Progressive Methods of Passenger Handling}

Empirical research was used to find out if respondents knew technologies used in progressive methods of passenger handling, namely the acronym NFC (Near Field Communication - this technology is part of all smartphones and tablets), EMV (Europay/MasterCard/VISA - a global standard for credit and debit cards which is used in each cashless payment), and ABT (Account Based Ticketing - it uses electronic ID cards, debit and credit cards to identify a passenger and subsequently to calculate a fare; no other chip card is needed) $[9,10]$. Respondents could have marked several responses, not only one of them. More than half of respondents $(53.90 \%)$ stated they did not know any of the acronyms. The second group of respondents replied they knew the acronym NFC (33\%). The EMV technology was known only by $16.5 \%$ respondents. At least $10.30 \%$ respondents were aware of the acronym ABT.

After that respondents were given explanations of the acronyms and technologies, so the interest in utilising these technologies in passenger transport could be determined. Based on these explanations respondents should have replied if they were interested in using some of those technologies. Again several responses could have been marked in this question. The majority of respondents replied they would be interested in using the NFC technology. The EMV technology, which is based on paying for a travel document by means of a payment card (which is currently used in cashless payment), would be interesting for $36.10 \%$ respondents. The ABT technology would be interesting for the least respondents $(30.80 \%)$; although lately this technology has been promoted abroad, which is related to electronic identification cards (ID cards) as well as the public equipped with credit and debit cards. Other respondents $(12.90 \%)$ have no interest in using any of the given technologies.

The above mentioned technologies enable variations in consideration of logging in and logging off the system for passenger handling, namely the connection:

- check in/check out - a passenger is required to hold their ID card or active NFC mobile phone near a scanning device before each beginning of a journey and after completing the journey. After holding the card near the scanning device upon the journey completion the fare is deducted. [11-13]:

- walk in/walk out - scanning devices are placed near the door of transport means within public passenger transport. Passengers identify themselves using their ID card or active mobile phone with a carrier's mobile application enabled; the phone is hold near the scanning device at each walk in/walk out of the transport means.[14]

- be in/be out - identification of a contactless chip card or active NFC mobile phone during the journey. This way, passengers register themselves during the entire journey. [15]

Empirical research was used to find out a preferred kind of connection into and out of the system. The total number 519 of respondents was decreased in 66 respondents due to lack of interest in using cashless payment and new technologies. There was an assumption that not all respondents would understand the functioning of given connections, thus they were explained. Thanks to these explanations respondents would mostly utilise the connection of walk in/walk out type $(46 \%)$ and the connection of check in/check out type $(40 \%)$. There are three login options mentioned above. The connection of be in/be out type was not offered in the research due to its investment intensity; instead respondents were offered the option to $\log$ into the system using a stationary automatic machine. This variant was marked by the least respondents (14\%).

\section{Conclusion}

On the basis of the realised empirical research in passengers' interest in new methods of passenger handling in railway transport in the territory of the Slovak Republic it may be concluded that passengers are mostly interested in the NFC technology which uses a contactless chip cards and mobile phones to identify 
passengers and pay for travel documents. Moreover, results of the realised empirical research imply that passengers would utilise the connection of walk in/walk out type between media and scanning devices which would be placed in the means of transport.

The NFC technology has been occurring on the transport market abroad for more than 10 years; it has been undergoing an innovation in the area of a cashless payment, so passengers can (besides a contactless chip card and mobile phone) use their payment card, too, to pay for a travel document.

The way of a cashless payment is also used in the EMV technology and the newest technology ABT which is currently applied also in the capital city of Hungary, Budapest, where (besides a payment card) electronic identification cards (ID cards) and national cards of carriers are used in order to identify a passenger and to pay a fare $[14,16]$.

The paper is supported by the VEGA Agency by the Project 1/0791/18"The Assessment of Economic and Technological Aspects in the Provision of Competitive Public Transport Services in Integrated Transport Systems" that is solved at Faculty of Operations and Economics of Transport and Communication, University of Žilina.

\section{References}

1. L. Jedlinsky, J. Caban, L. Krzywonos, S. Wierzbicki, F. Brumercik, Journal of Vibroengineering, 17. 175187. (2015)

2. N. Nestorova, S. Goncharuk, V. Anisimov, A. Anisimov, V. Shvartcfel, Procedia Engineering. 165. 1547-1555. (2016)

3. D. Barta, M. Mruzek, M. Kendra, P. Kordos, L. Krzywonos, Advances in Science and Technology, 10. 240-247. (2016)
4. J. Danis, A. Dolinayova, J. Camaj, AER - Advances in Engineering Research. 62. 187-190. (2016)

5. L. Cerna, V. Zitricky, J. Danis, Open Engineering. 7. 6-13. (2017)

6. J. Masek, M. Kendra, Regulated and Unregulated Competition on Rails. 117-129. (2013)

7. Z. Krzysiak, G. B. Artnik, W. Samociuk, J. Zarajczyk, K. Plizga, B. Rachwal, S. Wierzbicki, L. Krzywonos, F. Brumercik, Przemysl Chemiczny. 96. 279-282. (2017)

8. L. Jedlinsky, J. Caban, L. Krzywonos, S. Wierzbicki, F. Brumercik, Journal of Vibroengineering. 17. 175187. (2015)

9. B. Abramovic, V. Zitricky, V. Biskup, European Transport Research Review. 8. (2016)

10. J. Dolinayova, J. Camaj, J. Kanis, Transport Problems, 12, 139-150, (2017)

11. J. Lalinska, J. Camaj, E. Nedeliakova. Transport Means - proceedings of the International Conference. 729-733. (2015)

12. J. Ližbetin, O. Stopka. Open Engineering. 6, 1. 441445. (2016)

13. V. Cempirek, P. Nachtigall, J. Siroky. Open Engineering, 6, 637-641, (2016)

14. D. Seidenglanz, M. Kvizda, T. Nigrin, Z. Tomes, J. Dujka. Journal of Transport Geography. 54. 414-429. (2016)

15. M. Poliak. Ekonomicky casopis. 61, 2. 206-220. (2013)

16. M. Kvizda, Rewiew Of Economic Perspectives. 17, 3. 331-334. (2017) 